\title{
Inhibition of the Bacterial Heme Oxygenases from Pseudomonas aeruginosa and Neisseria meningitidis: Novel Antimicrobial Targets
}

\author{
Lena M. Furci, ${ }^{\#}$ Pedro Lopes, ${ }^{\#}$ Suntara Eakanunkul, Shijun Zhong, Alexander D. MacKerell, Jr., ${ }^{*}$ and Angela Wilks* \\ Department of Pharmaceutical Sciences, School of Pharmacy, University of Maryland, 20 Penn Street, Baltimore, Maryland 21201-1140
}

Received January 24, 2007

The final step in heme utilization and iron acquisition in many pathogens is the oxidative cleavage of heme by heme oxygenase $(\mathrm{HO})$, yielding iron, biliverdin, and carbon monoxide. Thus, the essential requirement for iron suggests that HO may provide a potential therapeutic target for antimicrobial drug development. Computer-aided drug design (CADD) combined with experimental assays identified small-molecule inhibitors of the Neisseria meningitidis $\mathrm{HO}$ (nm-HO). CADD virtual screening applied to 800000 compounds identified 153 for biological assay. Several of the compounds were shown to have $K_{\mathrm{D}}$ values in the micromolar range for nm-HO and the Pseudomonas aeruginosa $\mathrm{HO}$ (pa-HO). The compounds also inhibited the growth of $P$. aeruginosa as well as biliverdin formation in $E$. coli cells overexpressing nm-HO. Thus, CADD combined with experimental analysis has been used to identify novel inhibitors of the bacterial heme oxygenases that can cross the cell membrane and specifically inhibit HO activity.

\section{Introduction}

The ability of bacterial pathogens to acquire iron is essential for both their survival and infectivity. In order to acquire iron, bacteria have evolved specialized systems to directly utilize iron from the host and from heme (iron protoporphyrin IX in any oxidation state) containing proteins. ${ }^{1-5}$ In a significant number of bacterial pathogens, the final step in heme utilization is the heme oxygenase (HO) dependent oxidative cleavage of the porphyrin macrocycle to biliverdin and carbon monoxide with the release of iron. ${ }^{6,7}$ Accordingly, as the final and critical step in iron utilization from heme, the bacterial heme oxygenases provide a unique therapeutic antimicrobial target.

A variety of Gram-negative pathogens, including those that cause many endemic and life-threatening diseases such as Neisseria meningitidis ${ }^{8}$ and Haemophilus influenzae, ${ }^{9}$ the causative agents of some forms of meningitis, and enteric pathogens such as Vibrio cholerae ${ }^{10,11}$ and Shigella dysenteriae $e^{12,13}$ have evolved sophisticated mechanisms for iron acquisition that involve direct utilization of heme-containing proteins. Neisseria meningitidis, an obligate human pathogen, is usually restricted to the nasopharynx but can invade the bloodstream and cause infections in the meninges and occasionally the synovial membranes of joints. ${ }^{14}$ Although little is known on the bioavailability of heme on human mucosal surfaces, Neisseria spp. show phase variation in the type of iron and heme receptors expressed in response to physiological and environmental conditions. ${ }^{15}$ This allows the bacteria to establish infections in environments where the heme availability may be extremely low through a combination of hemolysis and high-affinity outermembrane heme receptors that internalize the heme.

Heme uptake and utilization are also employed by opportunistic pathogens such as Pseudomonas aeruginosa, which has multiple systems for iron uptake, including two Furregulated heme uptake operons. ${ }^{16} P$. aeruginosa has become an increasing cause of nosocomial infections in immune compromised patients and is the primary cause of chronic lung

* To whom correspondence should be addressed. For A.D.M.: phone, 410-706-7442; fax, 410-706-5017; e-mail, amackere@rx.umaryland.edu. For A.W.: phone, 410-706-2537; fax, 410-706-5017; e-mail, awilks@ rx.umaryland.edu.

\# These authors contributed equally to this work. infections in individuals with cystic fibrosis $(\mathrm{CF})$ disease. ${ }^{17,18}$ In $\mathrm{CF}$ patients the virulence of $P$. aeruginosa is heightened by its ability to form biofilms, ${ }^{19-22}$ leading to antibiotic resistance profiles due to the inability to effectively eliminate the infective agent from such biofilms. ${ }^{21}$ Approximately $40 \%$ of CF patients succumb to fatal infection becasue of antibiotic-resistant $P$. aeruginosa infections. ${ }^{17}$ Notably, a knockout of the heme oxygenase gene in $P$. aeruginosa (pigA::gen) develops heme toxicity when heme is the sole iron source, ${ }^{23}$ suggesting that inhibiting pa- $\mathrm{HO}^{a}$ in vivo will result in toxicity and ultimately decreased virulence of the pathogen.

An important consideration in the design of a novel antibiotic is its specificity for the target protein. In the present case this consideration is in the context of the bacterial versus the human forms of heme oxygenase. Comparison of heme oxygenase from $N$. meningitidis (nm-HO) with the mammalian enzymes shows the solvent accessible surface to be significantly smaller in both nm-HO and pa-HO, $\sim 7.5 \AA^{3}$, when compared to their mammalian counterparts, which range from 43.6 to $59.7 \AA^{3} .^{24-27}$ Such a structural difference suggests that low molecular weight inhibitors of $\mathrm{nm}-\mathrm{HO}$ can be identified that are specific for the bacterial versus the human protein and thus may act as lead compounds in the development of potential antimicrobials.

A second consideration in the development of an antibiotic is its spectrum of activity. While most of heme oxygenases have a regioselectivity for the $\alpha$-meso carbon, which is released as $\mathrm{CO}$ to yield $\alpha$-biliverdin, the iron-regulated heme oxygenase of $P$. aeruginosa (pa-HO) is regioselective for the $\delta$-meso carbon. ${ }^{23}$ However, pa-HO shares $33 \%$ identity with nm-HO while both bacterial heme oxygenases have less than $15 \%$ homology with the mammalian enzymes, increasing the probability of identifying inhibitors specific for the bacterial enzymes. Thus, the potential exists for the development of novel antibiotics targeting nm-HO that may be specific for other bacterial pathogens while having the necessary specificity for bacterial over mammalian HOs.

${ }^{a}$ Abbreviations: pa-HO, Pseudomonas aeruginosa heme oxygenase; nmHO, Neisseria meningitidis heme oxygenase; MPA01, Pseudomonas aeruginosa PA01 strain; sGC, soluble guanylate cyclase; CYP, cytochrome P450; NOS, nitric oxide synthase; CADD, computer-aided drug design; MW, molecular weight. 


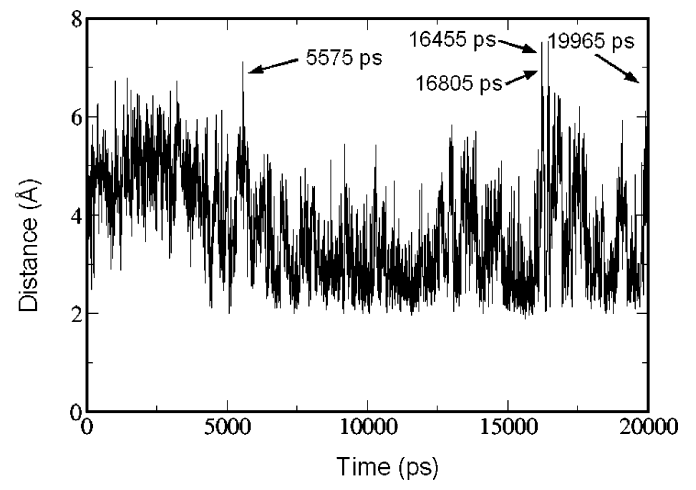

Figure 1. Distance between His-23 and Gly-116 as a function of time from the MD simulation of apo-nm-HO. Snapshots with the largest separations were selected for the docking procedures and are indicated by arrows.

A further consideration in exploiting $\mathrm{HO}$ inhibition as the basis for antibiotic development is the presence of siderophores secreted by many Gram-negative pathogens. Siderophores are high-affinity iron chelating complexes that sequester iron and actively transport the ferri-siderophore complex into the cell via a specific outer-membrane receptor. ${ }^{28}$ However, the availability of iron for microbial assimilation within the human host is extremely limited with the majority of iron sequestered in hemoglobin and other hemeproteins (approximately 95\%). Therefore, despite the presence of alternative mechanisms for iron uptake, during infection it is anticipated that blocking heme utilization has the potential to decrease the virulence of $N$. meninigitidis and $P$. aeruginosa, as well as other Gram-negative bacteria.

Discovery of novel inhibitors for a target protein can be greatly facilitated by the use of computer-aided drug design (CADD) ${ }^{29,30}$ In particular, virtual database screening approaches offer the potential to identify novel chemical entities with a high probability of binding to a target protein, as seen in a variety of studies. ${ }^{31-33}$ An essential requirement for the application of such screening approaches is the existence of 3D structural information on the target protein, information that is available for a number of heme oxygenases from different sources, including those of the human as well as the $N$. meningitidis, $C$. diphtheriae, and $P$. aeruginosa bacterial enzymes. ${ }^{24,27}$ In the present manuscript, by taking advantage of the 3D crystal structure of nm-HO combined with CADD approaches and experimental assays, we have identified novel inhibitors of nmHO. In addition, these compounds also inhibit the heme oxygenase from the opportunistic pathogen $P$. aeruginosa, indicating their potential for development into novel broadspectrum antibiotics.

\section{Results}

Database Screening. In silico database screening was performed to identify low molecular weight compounds with a high probability of binding to the heme pocket of nm-HO. To initiate this process, it was necessary to obtain conformations of the apo form of nm-HO (i.e., heme not bound) in which the heme binding pocket was in an "open" or accessible state. These were obtained via an MD simulation of the apo protein from the crystal structure of $\mathrm{nm}-\mathrm{HO}^{27}$ (as outlined in the Experimental Section). To identify such conformations, the accessibility of the heme binding pocket was monitored by following the His23 to Gly-116 distance as a function of time (Figure 1). From this plot it is evident that more accessible conformations of the binding pocket are sampled at the 5575, 16455,16805 , and
19965 ps snapshots. Accordingly, these four conformations of $\mathrm{nm}-\mathrm{HO}$ were selected for the database screening calculations.

Primary screening of the complete 800000 compound database of low molecular weight compounds that have druglike characteristics was performed using a single conformation: the 5575 ps structure from the MD simulation. The top 50000 compounds were selected from the primary screen based on the $N$ normalized van der Waals (vdW) attraction interaction energy. The normalization procedure corrects for the tendency of scoring, based on interaction energies, to be biased toward the selection of higher MW species, ${ }^{34}$ and use of the vdW attractive energy selects compounds that have good steric overlap with the protein thus avoiding compounds that have very favorable electrostatics but do not have shape complementarity with the binding pocket. The selection procedure yielded a distribution with an average MW of $279 \pm 77 \mathrm{Da}$, a value that is ideal for studies in which lead compounds are to be identified. ${ }^{35}$ The selection of MW compounds in this range facilitates future lead optimization of the active compounds, a process that tends to increase the MW of the lead compound during the optimization process. In addition, when the number of low MW compounds selected is increased, it is anticipated that absorption and disposition properties of those compounds will be improved. ${ }^{36,37}$

The 50000 compounds from the primary screen were then subjected to a secondary screen. In this screen conformational flexibility of the protein is partially taken into account by screening the 50000 compounds against four protein conformations. Moreover, additional energy minimization is included during the secondary docking to improve the accuracy of the docked poses and of the scores. Because compounds dominated by favorable electrostatics were excluded in the primary screen, scoring for the secondary screen was performed using the total interaction energy along with $N^{3 / 5}$ normalization to obtain a desirable MW distribution. ${ }^{34}$ From this process the top 1000 compounds were selected.

Compounds selected from the DOCK based database screening may be assumed to all structurally complement the target binding site and, thus, have the potential to bind to the protein. However, as we cannot evaluate all 1000 compounds experimentally; it is desirable to select compounds from the 1000 that have maximal chemical diversity, an approach that has been used successfully by us in previous studies. ${ }^{38,39}$ Obtaining diverse compounds was performed via similarity clustering based on chemical fingerprints. This process leads to approximately 100 clusters, following which one or two compounds were selected from each cluster for biological assay. This selection process emphasized identifying compounds that followed Lipinski's rule of 5, although in cases where all compounds in a cluster did not meet the criteria, a compound was still selected for assay. From this process a total of 153 compounds were obtained from commercial vendors. Initial experimental screening of those 153 compounds showed 37 to be soluble in either buffer or DMSO; these compounds were subjected to further experimental studies. Of the 37 compounds, 10 were shown to have inherent fluorescence and were not analyzed further in the current study. The fluorescent compounds as well as the remainder of the 153 compounds initially selected that were insoluble are being further analyzed for inhibitory activity.

Experimental Studies. A series of experiments were undertaken on the 27 soluble compounds to identify those that both bind to $\mathrm{HO}$ in vitro and inhibit $\mathrm{HO}$ activity in vivo. In these experiments both nm-HO and pa-HO were tested for binding 


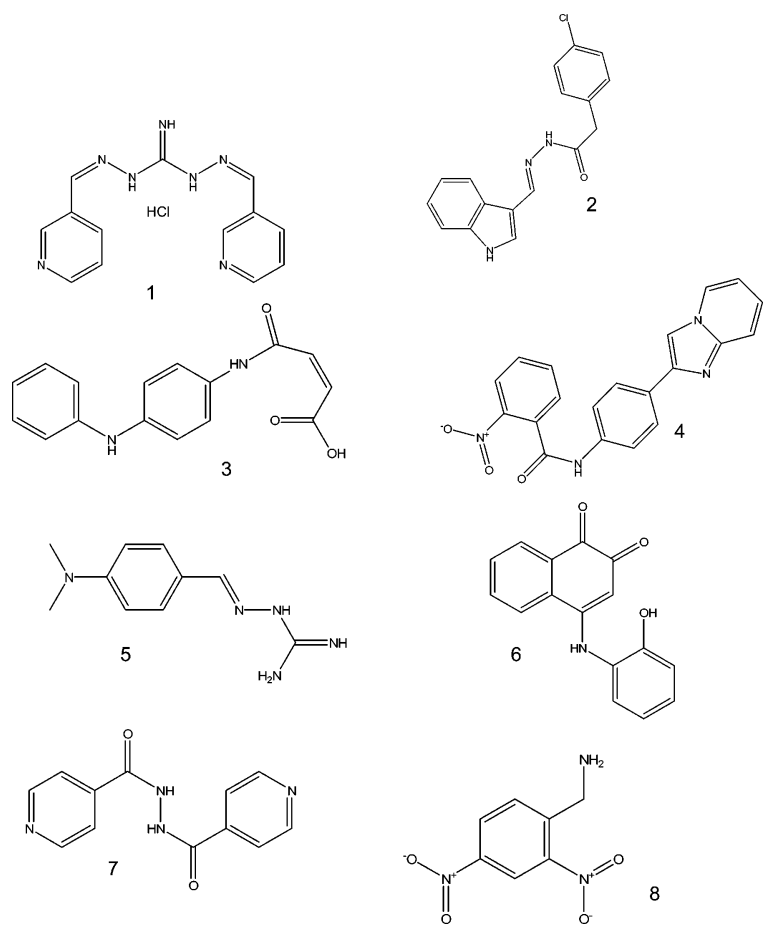

Figure 2. Chemical structures of the active compounds 1-8. All compounds were commercially purchased from manufacturers as identified and further described in the Experimental Section.

affinity and the ability to inhibit enzymatic activity either in an E. coli expression system (nm-HO) or in the bacterial strain itself (pa-HO). Accordingly, systems for in vitro and in vivo selection were employed for both proteins in identifiying biologically active compounds targeted to an inherently virulent pathogen $N$. meningitidis and an important opportunistic pathogen $P$. aeruginosa.

Binding Affinities $\left(K_{\mathrm{D}}\right)$ of Selected Compounds. The initial experimental selection criterion was the ability of the compounds to bind to heme oxygenase, as determined by fluorescence quenching of the protein. Compounds were first tested for their excitation/emission spectral profiles to ensure they would not interfere with the emission profile of the purified protein. Of the 37 compounds, 8 were shown to have no intrinsic fluorescence associated with the compound but to have reduced protein (tryptophan) fluorescence when added in 10-fold excess. It is noted that in ongoing studies we are re-evaluating compounds that were insoluble or precluded from fluorescence screening because of intrinsic fluorescence based on NMR methods and $\mathrm{MIC}_{50}$ assays with $P$. aeruginosa to identify a wide range of potential lead compounds.

The structures of the compounds that quenched protein fluorescence $(\mathbf{1}-\mathbf{8})$ are shown in Figure 2. The binding affinities ( $K_{\mathrm{D}}$ values) of the selected compounds calculated by the fluorescence titrations against both pa- $\mathrm{HO}$ and $\mathrm{nm}-\mathrm{HO}$ are given in Table 1. The binding affinities for the selected compounds were all in the micromolar range. These eight compounds were then subjected to additional experimental analysis as described below.

Inhibition of Biliverdin Production in an $E$. coli System Expressing nm-HO. The eight compounds were next assessed for their ability to inhibit the production of $\alpha$-biliverdin in $E$. coli cells expressing nm-HO. Several of the compounds $(\mathbf{1}-\mathbf{5})$ inhibited the production of $\alpha$-biliverdin in an E. coli expression system as judged by the lack of pigmentation in the cells (Table 1 and Figure 3A). Extraction and HPLC analysis of the products from untreated cells or cells treated with compound $\mathbf{3}$ confirmed
Table 1. Binding Affinities and Inhibition of nm-HO Activity by Compounds 1-8

\begin{tabular}{clcc}
\hline & \multicolumn{2}{c}{ binding affinity $\left(K_{\mathrm{D}}\right)(\mu \mathrm{M})$} & $\begin{array}{c}\text { E. coli assay } \\
\text { compd }\end{array}$ \\
\cline { 2 - 3 } & \multicolumn{1}{c}{ pa-HO } & nm-HO & biliverdin pigmentation ${ }^{a}$ \\
\hline $\mathbf{1}$ & $15.9 \pm 1.1$ & $12.2 \pm 1.0$ & - \\
$\mathbf{2}$ & $15.8 \pm 1.0$ & $14.1 \pm 2.6$ & - \\
$\mathbf{3}$ & $20.1 \pm 1.8$ & $15.6 \pm 1.9$ & - \\
$\mathbf{4}$ & $6.1 \pm 0.5$ & $20.9 \pm 4.5$ & - \\
$\mathbf{5}$ & $30 \pm 1.8$ & $22.9 \pm 2.8$ & - \\
$\mathbf{6}$ & $72.8 \pm 5.3$ & $28.8 \pm 3.3$ & + \\
$\mathbf{7}$ & $44.7 \pm 6.9$ & $33.5 \pm 4.1$ & + \\
$\mathbf{8}$ & $187.3 \pm 14$ & $239 \pm 21$ & nd \\
\hline
\end{tabular}

${ }^{a}+$, biliverdin observed in cell pellet. - , biliverdin not observed. nd, not determined because of toxicity of the compound.

that the lack of pigmentation was due to the inhibition of $\alpha$-biliverdin production (Figure 3B). As an internal standard, the product of the pa-HO reaction, which is a 30:70 ratio of $\beta$-biliverdin $/ \delta$-biliverdin, was added to the lysed cells prior to extraction of the reaction products. As shown in Figure $3 \mathrm{~B}$, the extraction of biliverdin from untreated and cells treated with $1500 \mu \mathrm{M}$ compound 3 yielded similar levels of the internal standard ( $\beta$-biliverdin $/ \delta$-biliverdin). In stark contrast, a marked decrease in the $\mathrm{nm}-\mathrm{HO}$ catalyzed $\alpha$-biliverdin product is observed in the cells treated with compound 3. Integration of the $\alpha$-biliverdin peak from the control culture compared to the treated cells (accounting for the levels of the extracted internal standard) gave an estimate of a $60 \%$ decrease in $\alpha$-biliverdin product as a consequence of nm-HO inhibition.

Growth Inhibition of $\boldsymbol{P}$. aeruginosa MPA01. Compounds 1-8 were further analyzed for their ability to inhibit the growth of MPA01 when given heme as the sole source of iron. MPA01 growth inhibition when heme is the iron source is a strong indication that $\mathrm{HO}$ activity plays a central role in obtaining iron necessary for cell viability. Compounds $\mathbf{1}-\mathbf{8}$ at $10-1500 \mu \mathrm{M}$ were assessed for the ability to inhibit growth in 96-well growth assays. None of the compounds tested inhibited the growth of MPA01 below $250 \mu \mathrm{M}$, whereas compounds $\mathbf{2}$ and $\mathbf{3}$ appeared to significantly decrease the growth of MPA01 at concentrations greater than $250 \mu \mathrm{M}$ (data not shown). In order to determine if the growth end-points observed in the 96-well assays resulted from a slower growth rate versus cell death, the growth of MPA01 in the presence of $\mathbf{2}$ or $\mathbf{3}$ was monitored in larger cultures at a single $10 \mathrm{~h}$ time point and over the complete growth curve (Figures 4 and 5).

The growth inhibition of MPA01 in the presence of $\mathbf{2}$ or $\mathbf{3}$ was monitored at a final $10 \mathrm{~h}$ time point with selected compound concentrations ranging from 10 to $1500 \mu \mathrm{M}$. MPA01 cultures grown under iron-restricted conditions in the absence or presence of the compounds did not show a significant difference in growth, indicating that the compounds themselves were not toxic to the cells (Figure 4). Furthermore, inhibitory effects of $\mathbf{2}$ or $\mathbf{3}$ at $250 \mu \mathrm{M}$ and above could be overcome on addition of $\mathrm{Fe}$ (III) pyoverdine $(40 \mu \mathrm{M})$, an alternative iron source not dependent on $\mathrm{HO}$ activity, to the cultures. At concentrations of $\mathbf{3}$ at 500 $\mu \mathrm{M}$ and above, a slight inhibitory effect was observed even in the presence of $\mathrm{Fe}(\mathrm{III})$ pyoverdine (Figure $4 \mathrm{~B}$ ). In contrast, when hemoglobin was provided as the sole iron source, the cultures in the absence of $\mathbf{2}$ or $\mathbf{3}$ attained optical densities similar to those of iron-replete media, whereas those in the presence of the compound recovered approximately $40 \%$ of the growth of the control cultures with $\mathrm{Fe}(\mathrm{III})$ pyoverdine as an iron source (parts B and C of Figure 4). The present data are consistent with the observation presented above in which there is reduction of the $\alpha$-biliverdin product in the $E$. coli expression system in the presence of $\mathbf{3}$, suggesting that direct inhibition of HO activity 
A

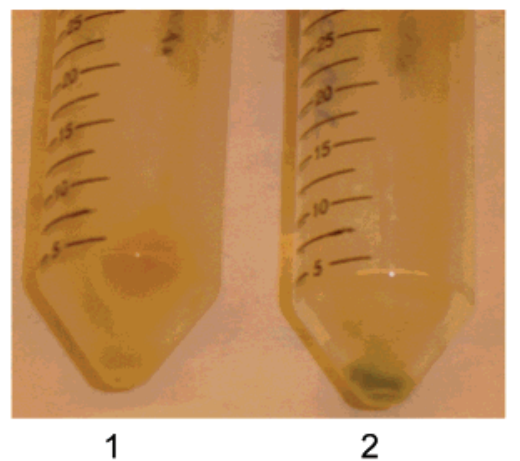

B

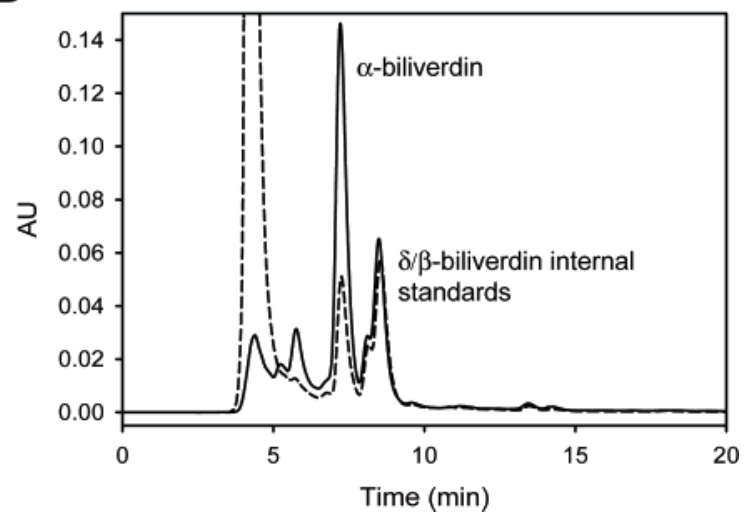

Figure 3. Inhibition of nm-HO in an E. coli expression system: (A) cell pellets of cultures either treated with $1500 \mu \mathrm{M}$ compound 3 (1) or untreated (2); (B) HPLC analysis of the extracted products of the compound treated (- - ) and untreated (-) cultures. The peak observed at 3-5 min in the treated cultures is due to the extracted compound. The shoulder on the internal standard peak is due to $\beta$-biliverdin. Extraction and HPLC analysis were carried out as described in the Experimental Section.
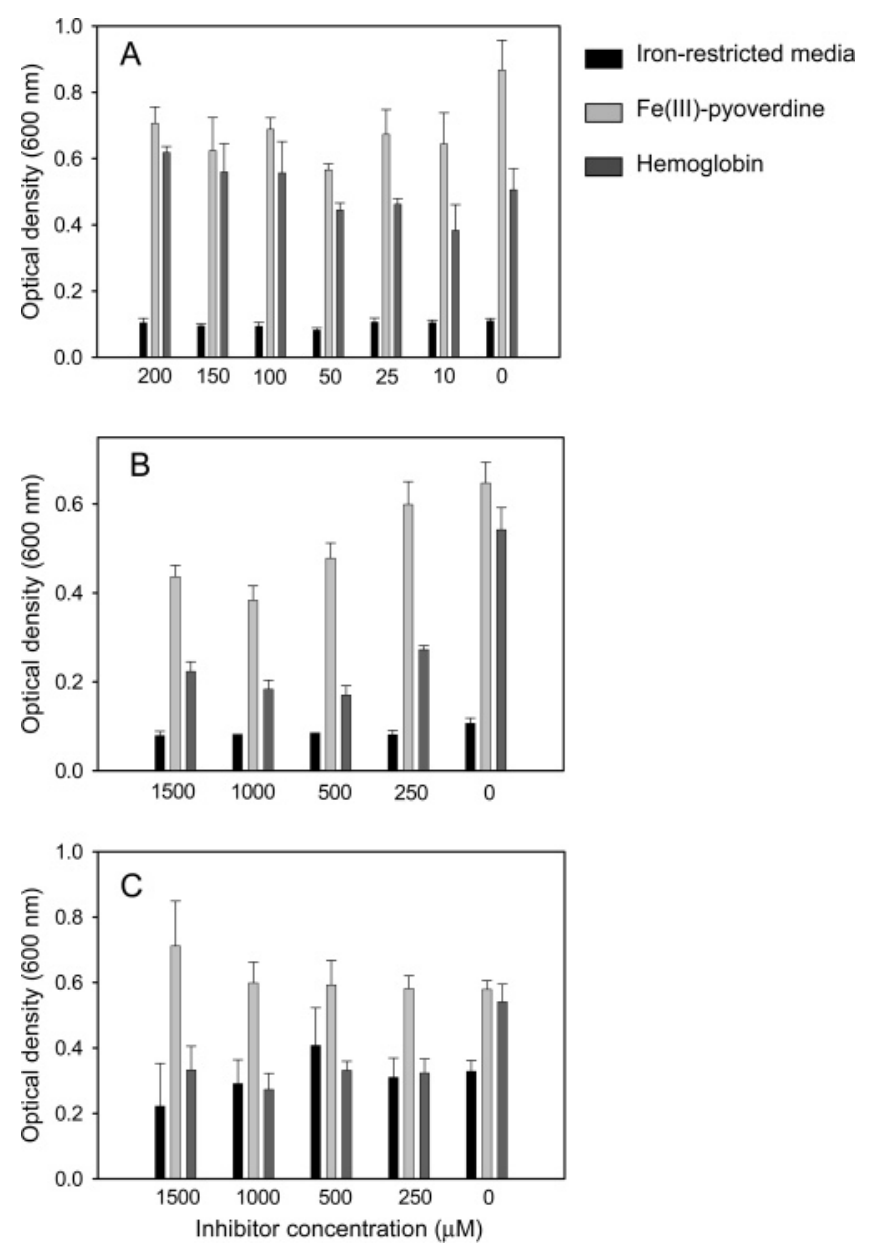

Figure 4. Growth analysis of $P$. aeruginosa MPA01 in the presence of various concentrations of compounds $\mathbf{2}$ and $\mathbf{3}$ as a function of iron source. Cultures $(10 \mathrm{~mL})$ were grown from an initial $\mathrm{OD}_{600}$ of 0.05 for $10 \mathrm{~h}$ in iron-restricted SM medium in the presence or absence of compound at various concentrations. Where indicated, the cells were supplemented with $\mathrm{Fe}(\mathrm{III})$ pyoverdine or hemoglobin as an iron source: (A) compound 3 at $0-200 \mu \mathrm{M}$; (B) compound 3 at $0-1500$ $\mu \mathrm{M}$; (C) compound 2 at $0-1500 \mu \mathrm{M}$.

is also responsible for the growth inhibition observed in the MPA01 strain.

It was further determined that the inhibition of growth of MPA01 in vivo was due to a slower growth rate over a $6 \mathrm{~h}$ period. As shown in Figure 5A, in the presence of $3(500 \mu \mathrm{M})$ the slower growth rate in iron-restricted media could be largely
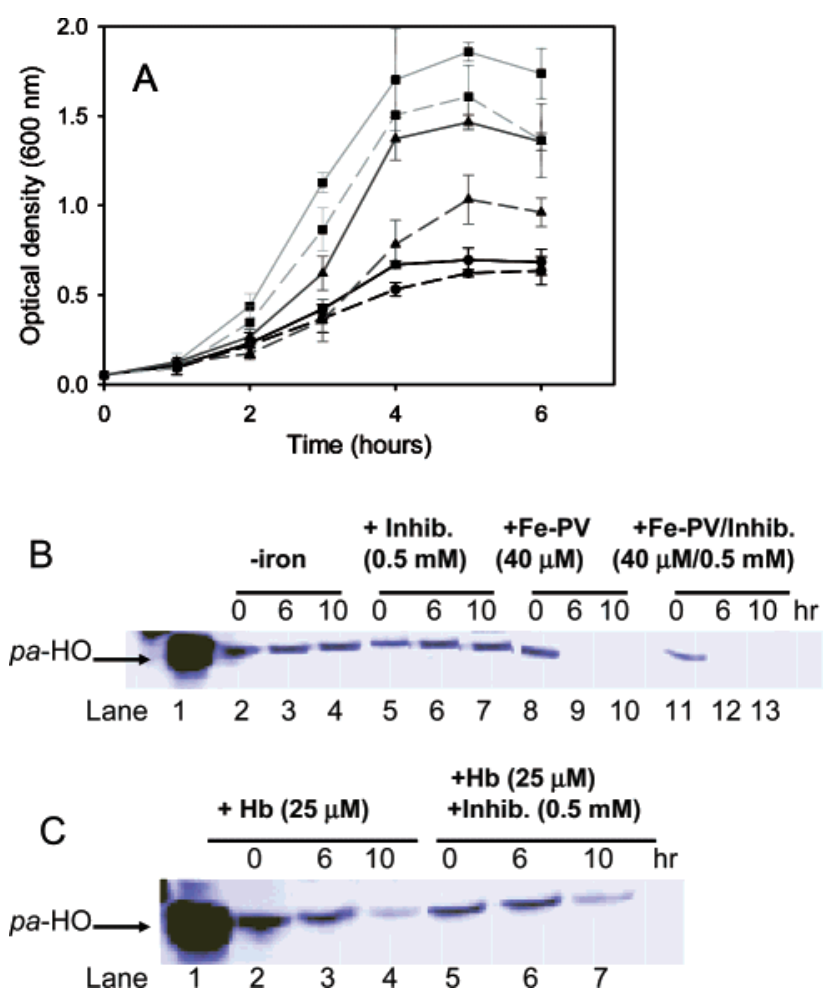

Figure 5. Growth inhibition and pa-HO protein expression levels of $P$. aeruginosa MPA01 in the presence of compound 3. Cultures of $P$. aeruginosa PA01 $(12 \mathrm{~mL})$ at a starting $\mathrm{OD}_{600}$ of 0.05 were grown over a $12 \mathrm{~h}$ period in iron-restricted media in the presence or absence of compound $3(500 \mu \mathrm{M})$. The data are the average of three separate experiments: (A) growth curve of MPA01 in iron-restricted media in the absence of compound $(--)$ or in the presence of compound (- -); MPA01 supplemented with $40 \mu \mathrm{M} \mathrm{Fe}$ (III) pyoverdine (- - ) or $40 \mu \mathrm{M} \mathrm{Fe}(\mathrm{III})$ pyoverdine in the presence of compound (- - -); MPA01 supplemented with $25 \mu \mathrm{M}$ hemoglobin as the iron source $(-\boldsymbol{\Delta}-)$ or $25 \mu \mathrm{M}$ hemoglobin in the presence of compound (- $\boldsymbol{\Delta}-)$; (B) Western blot analysis of pa-HO expression levels with or without compound 3 when supplemented with $40 \mu \mathrm{M}$ Fe(III) pyoverdine; (C) Western blot of pa-HO expression with or without compound 3 supplemented with $25 \mu \mathrm{M}$ hemoglobin.

overcome on addition of $\mathrm{Fe}(\mathrm{III})$ pyoverdine. However, in the presence of hemoglobin as the sole iron source, the inhibition of growth was not overcome or restored to the levels observed for the $\mathrm{Fe}(\mathrm{III})$ pyoverdine supplemented cultures. In addition, the slow growth rate of the bacterial cultures was shown to be due to inhibition of enzymatic activity of $\mathrm{HO}$ and not altered 
levels of protein expression as judged by Western blot analysis (Figure 5B). Under iron-restricted conditions, as would be expected, the HO levels are up-regulated. Additionally, it was noted that in the presence or absence of $\mathbf{3}$ no significant difference in protein expression levels was observed. However, when supplied with $\mathrm{Fe}(\mathrm{III})$ pyoverdine, the HO levels decrease significantly and are undetectable after $6 \mathrm{~h}$ as the cells begin to utilize the iron provided by the siderophore uptake pathway (Figure 5B). ${ }^{8}$ Similarly, the levels of $\mathrm{HO}$ expression decrease over time when hemoglobin is provided as the source of iron (Figure 5C). ${ }^{8}$ The uptake and utilization of heme increase the cellular iron levels, initiating the Fur-dependent down-regulation of the heme uptake genes, including HO. However, the protein levels are still detectable after $6 \mathrm{~h}$ in the presence of hemoglobin versus $\mathrm{Fe}(\mathrm{III})$ pyoverdine, as heme appears to be a positive regulator of $\mathrm{HO}$ expression, whereas when iron is supplied via the siderophore pathway, the heme uptake genes are downregulated more rapidly. These results taken together indicate that the compound, when taken up by the bacteria cells, has no direct effect on the expression levels of the HO protein, further confirming that the decrease in biliverdin is solely due to inhibition of HO enzyme activity.

\section{Discussion}

The underlying premise for the CADD described in the current studies was to select small-molecule inhibitors of the $\mathrm{nm}-\mathrm{HO}$ apoprotein that are not analogues of heme or utilize coordination via the iron of the heme. This is in contrast to previous studies where it has been shown that metal substituted porphyrins are effective competitive inhibitors of mammalian heme oxygenase. ${ }^{40-43}$ Some of these inhibitors, such as $\mathrm{Zn}(\mathrm{II})$ protoporphyrin IX and Sn(IV) protoporphyrin IX, have been used as therapeutic agents in the treatment of neonatal jaundice, a condition attributed to increased $\mathrm{HO}$ activity in newborn infants. However, because of the identical structural motif of the porphyrin macrocycle, such inhibitors have limited selectivity in that other heme-containing proteins including the cytochromes P450 (CYP), nitric oxide synthase (NOS), and soluble guanylate cyclase (sGC) are susceptible to metalloporphyrin inhibition. ${ }^{44-46}$ Heme oxygenase inhibitors developed more recently include the imidazole-dioxolanes which have been shown to selectively inhibit the mammalian HO-1 (inducible) versus the HO-2 (constitutive) isoform. ${ }^{47}$ The dioxolane inhibitors were developed by synthetic modification of the lead compound azalanstat, an inhibitor of lanosterol $14 \alpha$-demethylase, a fungal CYP and a critical enzyme in the lanosterol biosynthetic pathway. ${ }^{48}$ While these inhibitors are selective in that inhibition of sGC, NOS, and the CYP isoforms 3A1/3A2 and CYP2E1 were not observed in vitro, it is hypothesized that by focusing on developing small-molecule inhibitors that bind specifically to the apoprotein rather than compounds that coordinate to the heme iron, we can further increase the selectivity toward HO. This approach, combined with the dramatic difference in active site volume between the bacterial $\mathrm{nm}-\mathrm{HO}$ and pa-HO versus the mammalian enzymes, discussed above should allow us to develop more selective inhibitors based on our initial lead compounds. However, the current approach has been shown to be effective in identifying inhibitors of the bacterial heme oxygenases, where 8 (Figure 2) of the 27 soluble compounds initially tested were shown to bind to $\mathrm{HO}$ in vitro and to inhibit HO activity in vivo. The active compounds will be further tested for selectivity toward the bacterial versus the mammalian heme oxygenases.

The predicted orientations of active compounds 1, 2, 5, 7, and 8 bound to apo nm-HO are shown in Figure 6. Analysis of
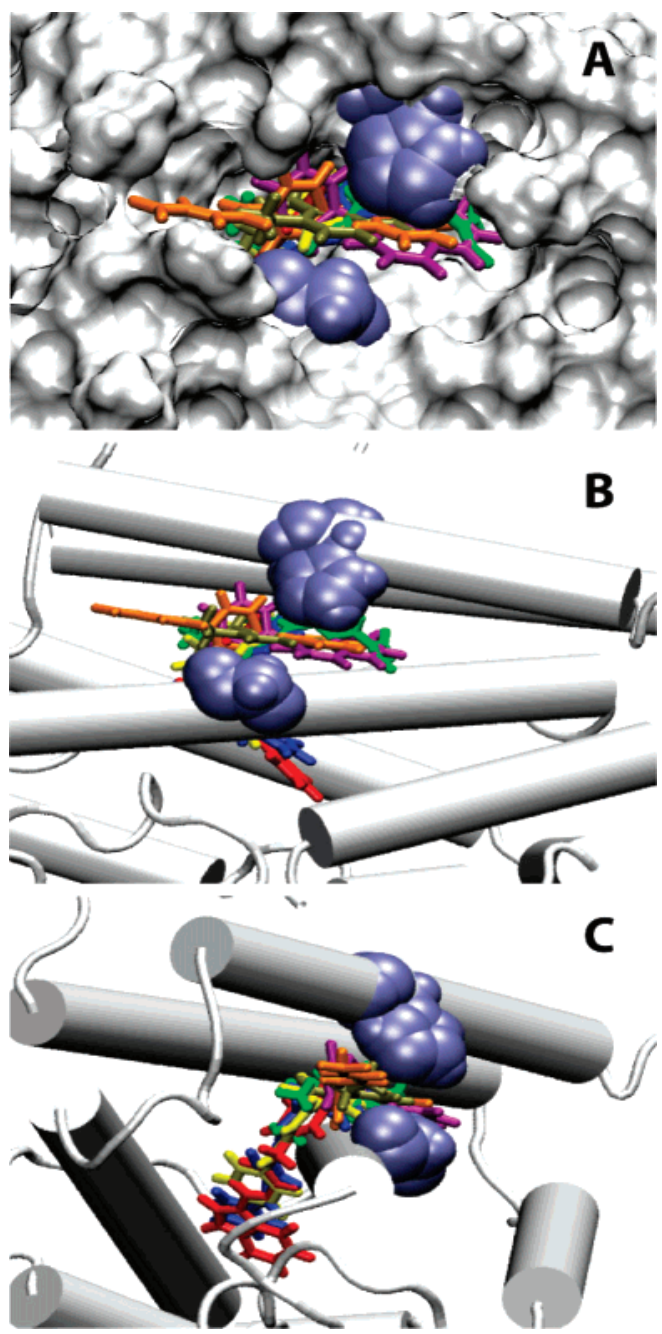

Figure 6. Images of selected active compounds bound to the heme oxygenase conformation from the 19965 ps snapshot of the trajectory. Compounds 1 (blue), 2 (red), 3 (orange), 5 (green), 6 (purple), 7 (yellow), and $\mathbf{8}$ (olive) were selected in the secondary screen based on the most favorable interaction energy and are shown in each panel. Protein residues His-23 and Gly-116 are shown as purple space filling representations, and the five docked compounds are shown in licorice format with each being assigned a separate color as indicated above: (A) surface representation of heme oxygenase viewing directly into the heme binding pocket; (B) cartoon representation in an orientation similar to that of (A) with the scale decreased; (C) cartoon representation that is an approximately $90^{\circ}$ rotation of the view in (B).

Figure 6A shows two of the compounds to span the heme binding pocket, residing between His-23 and Gly-116 and taking advantage of a range of interactions within the binding pocket. Interestingly, several of the compounds bind in a region in the back of the heme pocket previously identified in several bacterial crystal structure(s). The extent to which these compounds sample that region is particularly clear in Figure 6C, where it is seen that the compounds wrap around the proximal helix, binding well below the heme binding region. Binding to this region is particularly interesting in that it may facilitate the identification of compounds that bind specifically to heme oxygenases without having significant interactions with other heme binding proteins that do not contain such a pocket. Furthermore, this region of the pocket is significantly larger in the mammalian $\mathrm{HO}$ enzymes where a pronounced channel runs from the back of the cavity to the surface of the protein. ${ }^{26}$ Future docking studies will more rigorously investigate the interactions of the lead compounds 
with this binding site as a means of identifying inhibitors that are selective toward the bacterial ${ }^{25,27}$ versus the human HO. ${ }^{26}$

Several of the compounds were shown to bind to both pa$\mathrm{HO}$ and nm-HO with binding affinities $\left(K_{\mathrm{D}}\right)$ in the micromolar range (Table 1 and Figure 2). The affinity of heme for the bacterial heme oxygenases ranges from 1 to $5 \mu \mathrm{M} ;{ }^{23,49-51}$ however, it should be noted that in vivo heme is delivered to HO by a heme-trafficking protein, indicating that "free" heme binding affinities may not be relevant to the in vivo mechanism of heme inhibition.52,53 Further biological screening of the compounds revealed that in addition to in vitro binding to the HO proteins, many of the compounds also inhibited $\alpha$-biliverdin production in $E$. coli cells expressing nm-HO (Table 1 and Figure 3). E. coli cells expressing nm-HO were not subjected to iron restriction and no significant decrease in cell density was observed between the untreated and treated cells, confirming that the compounds were not toxic to the cells. Cells expressing nm-HO have increased pigmentation due to the presence of biliverdin; however, cells in the presence of $\mathbf{3}$ showed a significant decrease in pigmentation. Extraction and HPLC analysis of the product in the presence of $\mathbf{3}$ confirmed a reduction in biliverdin production (Figure $3 \mathrm{~B}$ ). These data taken together suggest that $\mathbf{3}$ is taken up by the bacterial cells and specifically targets $\mathrm{HO}$ enzymatic activity as judged by decreased biliverdin formation.

A critical factor in the current studies is the ability of the compounds, presumably by passive diffusion, to cross the bacterial cell membrane and to directly target $\mathrm{HO}$ activity under conditions where iron is limiting. The ability of the selected compounds to accumulate in cells and to inhibit endogenous pa-HO was further evaluated in the laboratory strain MPA01. The initial screening of 1-7 all indicated some degree of inhibition in the presence of heme as the sole source of iron (data not shown). The only exception was $\mathbf{8}$, which was toxic to the cells at concentrations above $250 \mu \mathrm{M}$ (data not shown). Further analysis of $\mathbf{2}$ and $\mathbf{3}$ indicated significant inhibition of $P$. aeruginosa in iron-restricted conditions supplemented with heme as the sole source of iron. In contrast, the iron restriction of growth can be overcome even in the presence of $\mathbf{2}$ and $\mathbf{3}$ when iron is given in the form of Fe(III) pyoverdine. These observations indicate that the compounds tested inhibit the growth of $P$. aeruginosa under conditions of iron limitation where heme is the sole source of iron.

Although the in vitro $K_{\mathrm{D}}$ values of all of the compounds tested were in the $5-30 \mu \mathrm{M}$ range and the growth rates of MPA01 were inhibited at values greater than $250 \mu \mathrm{M}$, it is evident that the concentrations of $\mathbf{2}$ and $\mathbf{3}$ being reached within the cell are sufficient to compete with exogenously acquired heme for binding to HO. Additionally, it was noted that there was no significant difference in $\mathrm{HO}$ protein expression levels between cultures grown in the presence or absence of the compound, confirming inhibition of enzymatic activity rather than a decrease in total protein. Furthermore, although the structures of many of the compounds suggest they may be iron chelators, the growth rates of $P$. aeruginosa were similar in iron-replete media containing the compounds compared to those in the absence of the compounds. This would indicate that the compounds are not effectively chelating iron and reducing its bioavailability. Additionally, in iron-replete media containing $\mathbf{3}$ no increase in iron-dependent HO expression was observed in P. aeruginosa, which also indicates that the cells are not sensing iron-restricted conditions. These results are consistent with the observation that E. coli cells expressing nm-HO show decreased levels of biliverdin production in iron-replete media but no inhibition in growth rate or cell densities.

Therefore, on the basis of the previous observations, we hypothesize that under the iron-restricted conditions encountered by the organism on colonization, in which iron is sequestered in storage proteins (ie. ferritin and lactoferrin) and where heme may be a primary source of iron, the ability of the pathogen to establish an infection will be compromised in the presence of inhibitors targeted to heme utilization. ${ }^{14}$ Indeed, it has recently been shown that for Staphylococcus aureus, heme is the preferred source of iron during the initial stages of infection. ${ }^{54}$ However, while the levels of heme available to pathogens under different physiological conditions and disease states are not known, the high-affinity outer-membrane receptors allow bacteria to survive in environments where the heme may be extremely low. This is evident in the case of Haemophilus influenzae and Porphyromonas gingivalis, both of which have an absolute requirement for heme, as they lack the heme biosynthesis genes, and yet can successfully colonize the nasoand oropharynx, respectively. ${ }^{55,56}$ Therefore, even in environments where heme is extremely low, a slight degree of hemolysis induced by the action of secreted virulence factors would significantly increase the levels of hemoglobin available to the bacterial pathogen. In $P$. aeruginosa, secretion of the redox active pyocyanin virulence factor contributes to tissue damage and inflammation, increasing the availability of heme to the bacteria. ${ }^{17,18,57,58}$ Indeed, the levels of human HO-1 in the lungs of $P$. aeruginosa infected CF patients have been shown to be up-regulated in a cytoprotective response to bacterial induced oxidative stress and inflammation, highlighting the host's response in restricting access of the pathogen to heme. ${ }^{59}$ Therefore, by effectively eliminating or restricting the ability of the pathogen to acquire and utilize heme, we would expect to see significant reduction in the virulence of the organism.

The compounds described herein are the first lead compounds developed to target the bacterial HOs and, more specifically, the apo-form of the enzyme. The compounds provide a first step in the development of potential antimicrobials that specifically target heme utilization as a mechanism in antimicrobial drug development. Although the current compounds lack many of the desirable features required for drug development, further screening and optimization of the current compounds by rational drug design methods, including identification and assay of analogues of the lead compounds, are anticipated to improve their biological efficacy.

The need to develop new antimicrobials, as well as new potential drug targets, is especially acute in the case of $P$. aeruginosa infections in CF patients, where the natural antibiotic resistance of the organism and the ability to form biofilms account for significant mortality in such patients. ${ }^{17,18,57}$ Therefore, the compounds described in this report provide the potential for a new class of antimicrobial agents to target infections that are persistently difficult to combat with the current spectrum of antimicrobial agents.

\section{Experimental Section}

In Silico Database Screening. Identification of putative inhibitors was performed by screening of a virtual database of over 800000 compounds $^{34}$ against the heme binding site of nm-HO. The virtual database represents a collection of low molecular weight compounds that are commercially available and predominately have druglike characteristics. ${ }^{60}$ The database is based on compounds from four commercial vendors (Chembridge, Chemdiv, Maybridge, and Specs) from which the respective computerized catalogs were obtained and converted from SDF format to 3D MOL2 format, 
energy-minimized, and assigned AM1/CM2 charges $^{61}$ as previously described. ${ }^{33,38,39,62}$ To obtain multiple conformations of the heme binding site suitable for database screening, the apo form of the protein (i.e., without the heme) was subjected to an MD simulation. From this simulation four conformations that had significant solvent accessibilities of the heme binding site were selected for the database screening. MD simulations and related calculations were performed with the program $\mathrm{CHARMM}^{63,64}$ using the all-hydrogen protein force field parameters, ${ }^{65}$ including the CMAP enhancement, ${ }^{66,67}$ and the TIP3P water model..$^{68}$ The CRYSTAL module ${ }^{69}$ in CHARMM was used for the periodic boundary conditions, and electrostatic interactions were treated using the particle mesh Ewald method..$^{70}$ Real space electrostatic and Lennard-Jones cutoffs were $12 \AA$ with a force switch smoothing function ${ }^{71}$ from 10 to $12 \AA$ for the Lennard-Jones term. The nonbond list was maintained to $14 \AA$ and heuristically updated. An integration time step of $2 \mathrm{fs}$, a temperature of $300 \mathrm{~K}$, and SHAKE to constrain the covalent bonds involving hydrogen atoms ${ }^{72}$ were used during the NPT simulation, which were performed using the Langevin piston algorithm. ${ }^{73}$

Preparation of the protein for the simulation was initiated by obtaining the 3D structure of nm-HO complexed with heme from the Protein Data Bank (PDB) ${ }^{74}$ (PDB identifier 1P3T); ${ }^{24}$ the amino acid numbering herein represents the full-length sequence of the protein. The porphyrin moiety was removed, and the resulting structure (3114 atoms) was solvated. Solvation was performed by overlaying the protein with a pre-equilibrated box of water containing sodium of dimensions $70.5 \AA \times 64.6 \AA \times 60.4 \AA$, which is approximately $10 \AA$ larger than the protein in all directions. All water or sodium ions with non-hydrogen atoms within $2.8 \AA$ of the protein non-hydrogen atoms were then deleted. Energy minimization of the solvent molecules was performed for 300 steepestdescent (SD) steps in the presence of periodic boundary conditions with the protein atoms harmonically restrained. The system was then equilibrated via a 20 ps NVT simulation $^{75}$ with the harmonic restraints maintained on the protein. This was followed by initiation of the production NPT simulation. This simulation was extended for $20 \mathrm{~ns}$ with the initial $1 \mathrm{~ns}$ considered for equilibration and with coordinates from the trajectory saved every 5 ps. Conformations from the MD simulations were then selected for database screening as described in the Results.

Primary database screening was performed on a single nm-HO conformation corresponding to the $5575 \mathrm{ps}$ snapshot from the MD simulation. Gasteiger charges were added to the protein using MOE (MOE, 2002; Chemical Computing Group Inc., Montreal, Quebec, Canada). Docking calculations were carried out with the DOCK program ${ }^{76}$ using flexible ligands based on the anchored search method $^{77}$ with posing based on the total ligand-protein interaction energy. The solvent accessible surface ${ }^{78}$ was calculated with the program DMS from the UCSF MIDAS package ${ }^{79}$ using a probe radius of $1.4 \AA$. Sphere sets, required for initial placement of the ligand during database screening, were calculated with the program SPHGEN, part of the DOCK package. Spheres that lay inside the binding pocket on each side of residue His-23 were selected for the search because each site may display separate binding affinities and specificities. Ligand-protein interaction energies were approximated by the sum of the electrostatic and van der Waals attractive components as calculated by the GRID method ${ }^{80}$ implemented in DOCK using default values. The GRID box dimensions were $30 \times 30 \times 36 \AA^{3}$ centered on a point placed approximately in the center of the binding pocket. During docking the posing of the ligands was based on the total interaction energy with the target protein; however, for primary screening, scoring was based on the attractive vdW interaction energy, as described in Results. Scoring for secondary screening used the total interaction energy.

The following operational parameters were applied in the docking runs. Database screening initially selected compounds containing 10 or fewer rotatable bonds and between 10 and 40 non-hydrogen atoms. Ligand flexibility was considered by dividing each compound into a collection of nonoverlapping rigid segments. Individual rigid segments with five or more heavy atoms (e.g., aromatic rings) were selected as "anchors". Each anchor was individually docked into the binding site in 200 separate orientations, based on different overlap of the anchor atoms with the sphere set, and was then energy-minimized. The remainder of each molecule was built onto the anchor in a stepwise fashion until the entire molecule was constructed, with each step corresponding to a rotatable bond. At each successive step the dihedral angle about the rotatable bond, which connected the new segment to the previously constructed portion of the molecule, was sampled in $10^{\circ}$ increments and the lowest energy conformation was then selected. During the buildup process, selected conformers were removed on the basis of energetic considerations and maximization of diversity of the conformations being sampled, as previously described. ${ }^{77,81}$ The ligand orientation with the most favorable interaction energy was selected.

Previous studies in our laboratory have shown that the DOCK energy score is biased toward the selection of high molecular weight compounds because of the contribution of the compound size to the energy score. ${ }^{34}$ Such biasing behavior was observed to depend on the shape and chemical properties of the binding pocket. Hence, a computationally efficient procedure was developed in which the energy score is normalized by the number of heavy atoms $N$ in each respective compound or by a selected power of $N$. This normalization approach shifts the molecular weight distribution of the selected compounds into better agreement with that of the entire database.

Compounds selected from the primary screen were subjected to a secondary screen. This screen involved a more rigorous minimization that included simultaneous energy minimization of the anchor fragment during the iterative buildup procedure. In addition, three additional conformations of the protein obtained from snapshots at 16405,16805 , and 19965 ps of the MD simulations were used such that each compound was docked individually against four conformations with the best score from the four runs used for final ranking of that compound. From the secondary screen, 1000 compounds were selected on the basis of the total interaction energy using $N^{3 / 5}$ normalization.

Selection of the final compounds for experimental assay involved maximizing the chemical diversity of the compounds as well as consideration of their physical properties. This was performed by dividing the 1000 compounds from the secondary docking into chemically dissimilar clusters by applying the Tanimoto similarity indexes ${ }^{82}$ using the program MOE. The clustering procedure started with the calculation of the molecular fingerprints, followed by the calculation of the pairwise Tanimoto similarity matrix $A(i, j)$ containing the similarity metric between the molecular fingerprints of compounds $i$ and $j$. From $A(i, j)$, a binary matrix $\mathbf{B}$ was created such that $B(i, j)$ has the value 1 if $A(i, j)$ is equal to or greater than $S$ or has the value 0 otherwise, where $S$ is a user selected similarity threshold that determines if two compounds are defined as similar. The rows of the $\mathbf{B}$ matrix were then treated as fingerprints, where two molecules belong to the same cluster if the Tanimoto coefficient of their corresponding rows in $\mathbf{B}$ is greater than or equal to $T$, a user selected overlap threshold. This results in two molecules being clustered together if they are similar to the same set of molecules. In the present study the similarity threshold was set to $70 \%$ and the overlap threshold was set to $40 \%$. Compounds for biological assay were selected from the dissimilar sets. This was performed by individually analyzing the clusters and selecting compounds from each cluster based on Lipinski's rule of $5,{ }^{83}$ including solubility $(\mathrm{ClogP} \leq 5)$, molecular weight $(\leq 500 \mathrm{Da})$, and the number of hydrogen bond donors $(\leq 5)$ and acceptors $(\leq 10)$. In addition, the chemical stability was considered. From 1000 compounds, a subset of 153 chemically diverse molecules were selected for biological assay and purchased from ChemBridge Corporation (San Diego, CA), ChemDiv Inc. (San Diego, CA), Maybridge (Cornwall, U.K.). and Specs (Cumberland, MD).

Bacterial Strains, Plasmids, and Media. Pseudomonas aeruginosa MPA01 (referred to as MPA01) was obtained from the University of Washington, Genome Center, Seattle, WA. The pa$\mathrm{HO}$ and nm-HO genes cloned into pET21a were transformed into E. coli strain BL21 (DE3) pLysS $\left[\mathrm{F}^{-}\right.$ompT hsdS $\mathrm{B}_{\mathrm{B}}\left(\mathrm{r}_{\mathrm{B}}{ }^{-} \mathrm{m}_{\mathrm{B}}{ }^{-}\right)$gal $d c m$ (DE3)] for protein expression as previously described. ${ }^{23,51}$ Luria 
Bertani (LB) broth was used for growth and maintenance of $E$. coli strains in the presence of ampicillin, $100 \mu \mathrm{g} / \mathrm{mL}$. MinA minimal medium plates were used for growth and maintenance of the MPA01 strain. Succinate minimal (SM) medium (pH 7.0) was used for all growth studies of $P$. aeruginosa.

General Methods. A stock solution of hemoglobin was prepared in SM medium ( $\mathrm{pH}$ 7.0). Pyoverdine was purified as described by Dr. Jean-Marie Meyer, Department de Genetique Moleculaire, Denomique et Micorbiologie, Strasbourg, France (personal communication). Briefly, a single colony of MPA01 was grown in 10 $\mathrm{mL}$ of $\mathrm{LB}$ medium for $16 \mathrm{~h}$. The culture was pelleted by centrifugation (4000 rpm for $10 \mathrm{~min}$ at $4{ }^{\circ} \mathrm{C}$ ) and resuspended in $1 \mathrm{~mL}$ of SM medium. A 1:1000 dilution was made into $1 \mathrm{~L}$ of SM and grown for $24 \mathrm{~h}$. Subsequently, the culture was harvested by centrifugation in a Beckman JA-10 rotor (10 $000 \mathrm{rpm}$ for $15 \mathrm{~min}$ ) at $4{ }^{\circ} \mathrm{C}$, and the resulting supernatant was acidified to $\mathrm{pH}$ 6.0. The acidified supernatant was applied to an Amberlite XAD-4 (Sigma) column $(2.5 \mathrm{~cm} \times 10 \mathrm{~cm})$ previously washed with $50 \%$ methanol $(\mathrm{MeOH})$ and extensively equilibrated with doubly distilled water. The column was washed with three volumes of water, and the pigment was eluted in $50 \% \mathrm{MeOH}$. The eluate was evaporated to dryness under vacuum and resuspended in $5 \mathrm{~mL}$ of water. The concentration of iron-free pyoverdine $(1: 1000)$ was determined in $0.5 \mathrm{M}$ acetic acid-sodium acetate buffer, $\mathrm{pH}$ 5.0, with an extinction coefficient at $340 \mathrm{~nm}$ of $\epsilon_{\max }=16500 \mathrm{M}^{-1} \mathrm{~cm}^{-1} .84$

A stock solution of $\mathrm{FeCl}_{3}(4.5 \mathrm{mM})$ was prepared in $0.5 \mathrm{M}$ sodium citrate for reconstitution of the holopyoverdine. A $2.5 \mu \mathrm{M}$ stock solution of apopyoverdine was reconstituted with $\mathrm{FeCl}_{3}$ at a 1:1 ratio to yield the resulting holopyoverdine. All compounds were prepared by solubilization in dimethyl sulfoxide (DMSO) and added directly to the cultures or purified protein in the concentrations stated. MPA01 growth inhibition assays were carried out in SM medium with a range of compound concentrations from 0 to 1500 $\mu \mathrm{M}$

Protein Purification.The wild-type apo-nm-HO and pa-HO proteins were purified using the previously described procedures. ${ }^{23,51}$ Following purification of the apoproteins, residual biliverdin was removed by passage of the protein over a PBE 94 chromatofocusing column $(1 \mathrm{~cm} \times 20 \mathrm{~cm})$ equilibrated in $0.025 \mathrm{M}$ imidazole $-\mathrm{HCl}$ ( $\mathrm{pH}$ 7.4). The apoprotein was eluted with a $\mathrm{pH}$ gradient from 7 to 4 with Polybuffer $74-\mathrm{HCl}(\mathrm{pH} 4.0)$. The proteins eluted at their respective $\mathrm{p} I$ values, and the Polybuffer was removed by ammonium sulfate precipitation and dialysis against $20 \mathrm{mM}$ Tris- $\mathrm{HCl}(\mathrm{pH} 7.5)$.

Measurement of the Binding Affinities $\left(K_{\mathrm{D}}\right)$ of the Selected Compounds. The results from binding of the compounds to apo$\mathrm{nm}-\mathrm{HO}$ and pa-HO were obtained by fluorescence titrations. Measurements were made on an ISS PC-1 spectrofluorimeter configured in the L format. Full excitation/emission spectra were recorded for each compound to determine the intrinsic fluorescence properties of the selected compounds. All experiments with either apo-nm-HO or pa-HO were carried out in $20 \mathrm{mM}$ Tris- $\mathrm{HCl}(\mathrm{pH}$ 7.5). The titrations were performed by addition of increasing concentrations of the selected compound $(0.05-500 \mu \mathrm{M})$ while maintaining the apo-nm-HO and pa-HO protein concentrations at $1 \mu \mathrm{M}$. The optimal excitation wavelength for the apoproteins was $295 \mathrm{~nm}$, and the fluorescence emission was monitored from 300 to $500 \mathrm{~nm}$. The dissociation constants $\left(K_{\mathrm{D}}\right)$ were calculated from reciprocal plots of $1 / \Delta A$ vs $1 /[\mathrm{I}]$ where the decrease in fluorescence, $\Delta A$, at the maximum emission $(330 \mathrm{~nm})$ represents the fraction of occupied binding sites and where $[\mathrm{I}]$ is the concentration of the compound. The slope of the curve equals $K_{\mathrm{D}}$, as described by the following equilibrium:

$$
\begin{gathered}
{[\mathrm{P}]+[\mathrm{I}] \rightleftharpoons[\mathrm{PI}]} \\
K_{\mathrm{D}}=\frac{[\mathrm{PI}]}{[\mathrm{P}]+[\mathrm{I}]}
\end{gathered}
$$

The binding affinities $\left(K_{\mathrm{D}}\right)$ of each compound for both nm-HO and pa-HO were measured and calculated on the basis of the average of three separate experiments.
Biliverdin Detection in an $E$. coli Expression System. The nm$\mathrm{HO}$ was expressed using modifications of a previously reported method. ${ }^{51}$ A single colony of freshly transformed E. coli BL21 (DE3) cells was cultured overnight in $10 \mathrm{~mL}$ of $\mathrm{LB}$ medium containing $100 \mu \mathrm{g} / \mathrm{mL}$ ampicillin. The leaky expression of $\mathrm{nm}-\mathrm{HO}$ in $E$. coli over a $16 \mathrm{~h}$ period gives rise to green pigmentation in the pellet as a result of heme turnover and $\alpha$-biliverdin production. The cells following overnight growth in the absence or presence of compound $3(1500 \mu \mathrm{M})$ were harvested by centrifugation ( $10000 \mathrm{~g}$ for $15 \mathrm{~min})$. The pelleted cells were lysed in $50 \mathrm{mM}$ Tris$\mathrm{HCl}$ buffer ( $\mathrm{pH}$ 7.4) containing $1 \mathrm{mM}$ EDTA, 2 mM desferroxamine, and $1 \mathrm{mM}$ PMSF, and to the the lysate was added purified $(50 \mu \mathrm{M}) \beta$-biliverdin $/ \delta$-biliverdin as an internal standard. The soluble fraction was then extracted into chloroform, and the organic layer was washed three times with water and dried. The dried residue was resuspended in $500 \mu \mathrm{L}$ of methanol containing $4 \%$ sulfuric acid and incubated for $6-8 \mathrm{~h}$. The resulting biliverdin dimethyl esters were washed with water $(\times 3)$, dried, and analyzed by HPLC as described previously. ${ }^{85}$

Growth Inhibition of Pseudomonas aeruginosa MPA01 in the Presence of Selected Compounds. A $15 \mathrm{~mL}$ culture of MPA01 was grown from a single colony for $8 \mathrm{~h}$ at $37^{\circ} \mathrm{C}$. The culture was diluted in SM medium to an $\mathrm{OD}_{600}$ of 0.05 . A 96-well plate assay was set up with $200 \mu \mathrm{L}$ of MPA01 cultures in SM medium alone or containing 250-1500 $\mu \mathrm{M}$ compound, $25 \mu \mathrm{M}$ hemoglobin \pm $250-1500 \mu \mathrm{M}$ compound, or $40 \mu \mathrm{M}$ holopyoverdine $\pm 250-1500$ $\mu \mathrm{M}$ compound where indicated. The cultures were incubated for $10 \mathrm{~h}$ at $37^{\circ} \mathrm{C}$ with aeration, at which point the $\mathrm{OD}_{600}$ for all wells was recorded on a SpectraMax Plus 96-well plate reader (Molecular Devices).

To determine the growth characteristics of MPA01, in the presence of compound, through log phase and entering early stationary phase, a $15 \mathrm{~mL}$ overnight culture was set up from a single colony of MPA01 in SM medium at $37{ }^{\circ} \mathrm{C}$ with shaking at 200 $\mathrm{rpm}$. The following day the overnight culture was diluted to an $\mathrm{OD}_{600}$ of 0.05 in $12 \mathrm{~mL}$ of $\mathrm{SM}$ medium containing $500 \mu \mathrm{M}$ compound, $25 \mu \mathrm{M}$ hemoglobin $\pm 500 \mu \mathrm{M}$ compound, or $40 \mu \mathrm{M}$ holopyoverdine $\pm 500 \mu \mathrm{M}$ compound where indicated. The cultures were grown with aeration at $37^{\circ} \mathrm{C}$, and the $\mathrm{OD}_{600}$ was measured every hour over a period of $12 \mathrm{~h}$. At 0,6 , and $10 \mathrm{~h}$ time points, 2 $\mathrm{mL}$ samples were collected for subsequent Western blot analysis. The pellets were lysed with approximately $350 \mu \mathrm{L}$ of lysis buffer containing $50 \mathrm{mM}$ Tris, $1 \mathrm{mM}$ EDTA, and $1 \mathrm{mM}$ PMSF. The samples were incubated on ice for $15 \mathrm{~min}$, sonicated briefly, and spun at $4{ }^{\circ} \mathrm{C}$ for $10 \mathrm{~min}$ to remove cell debris. The total protein concentration was determined by Bradford assay ${ }^{86}$ (Bio-Rad Laboratories, Hercules, CA). For each time point, a total of $5 \mu \mathrm{g}$ of protein in a final volume of $15 \mu \mathrm{L}$ was loaded onto a $12.5 \%$ SDS-PAGE gel. The expression of iron-regulated heme oxygenase, pa-HO, was confirmed by Western blotting as previously described $^{87}$ using a polyclonal antibody raised against pa-HO (Covance Research, Denver, PA).

Acknowledgment. This work was supported by NIH Award AI55912 (A.W.) and the University of Maryland ComputerAided Drug Design Center (A.D.M.).

\section{References}

(1) Braun, V. Iron uptake mechanisms and their regulation in pathogenic bacteria. Int. J. Med. Microbiol. 2001, 291, 67-79.

(2) Braun, V. Bacterial iron transport related to virulence. Contrib. Microbiol. 2005, 12, 210-233.

(3) Payne, S. M. Iron acquisition in microbial pathogenesis. Trends Microbiol. 1993, 1, 66-69.

(4) Wandersman, C.; Delepelaire, P. Bacterial iron sources: from siderophores to hemophores. Annu. Rev. Microbiol. 2004, 58, 611647.

(5) Wandersman, C.; Stojiljkovic, I. Bacterial heme sources: the role of heme, hemoprotein receptors and hemophores. Curr. Opin. Microbiol. 2000, 3, 215-220.

(6) Ortiz de Montellano, P. R.; Wilks, A. Heme oxygenase structure and mechanism. Adv. Inorg. Chem. 2000, 51, 359-402. 
(7) Wilks, A. Heme oxygenase: evolution, structure, and mechanism. Antioxid. Redox Signaling 2002, 4, 603-614.

(8) Zhu, W.; Hunt, D. J.; Richardson, A. R.; Stojiljkovic, I. Use of heme compounds as iron sources by pathogenic neisseriae requires the product of the hemO gene. J. Bacteriol. 2000, 182, 439-447.

(9) Sanders, J. D.; Cope, L. D.; Hansen, E. J. Identification of a locus involved in the utilization of iron by Haemophilus influenzae. Infect. Immun. 1994, 62, 4515-4525.

(10) Henderson, D. P.; Payne, S. M. Characterization of the Vibrio cholerae outer membrane heme transport protein HutA: sequence of the gene, regulation of expression, and homology to the family of TonB-dependent proteins. J. Bacteriol. 1994, 176, 3269-3277.

(11) Henderson, D. P.; Payne, S. M. Vibrio cholerae iron transport systems: roles of heme and siderophore iron transport in virulence and identification of a gene associated with multiple iron transport systems. Infect. Immun. 1994, 62, 5120-5125.

(12) Mills, M.; Payne, S. M. Genetics and regulation of heme iron transport in Shigella dysenteriae and detection of an analogous system in Escherichia coli O157:H7. J. Bacteriol. 1995, 177, 3004-3009.

(13) Mills, M.; Payne, S. M. Identification of shuA, the gene encoding the heme receptor of Shigella dysenteriae, and analysis of invasion and intracellular multiplication of a shuA mutant. Infect. Immun. 1997, 65, 5358-5363.

(14) Otto, B. R.; Verweij-van Vught, A. M.; MacLaren, D. M. Transferrins and heme-compounds as iron sources for pathogenic bacteria. Crit. Rev. Microbiol. 1992, 18, 217-233.

(15) Lewis, L. A.; Gipson, M.; Hartman, K.; Ownbey, T.; Vaughn, J.; Dyer, D. W. Phase variation of $\mathrm{HpuAB}$ and $\mathrm{HmbR}$, two distinct haemoglobin receptors of Neisseria meningitidis DNM2. Mol. Microbiol. 1999, 32, 977-989.

(16) Ochsner, U. A.; Johnson, Z.; Vasil, M. L. Genetics and regulation of two distinct haem-uptake systems, phu and has, in Pseudomonas aeruginosa. Microbiology 2000, 146 (Part 1), 185-198.

(17) Currie, A. J.; Speert, D. P.; Davidson, D. J. Pseudomonas aeruginosa: role in the pathogenesis of the CF lung lesion. Semin. Respir. Crit. Care Med. 2003, 24, 671-680.

(18) Elkin, S.; Geddes, D. Pseudomonal infection in cystic fibrosis: the battle continues. Expert Rev. Anti-Infect. Ther. 2003, 1, 609-618.

(19) Hall-Stoodley, L.; Costerton, J. W.; Stoodley, P. Bacterial biofilms: from the natural environment to infectious diseases. Nat. Rev. Microbiol. 2004, 2, 95-108.

(20) Parsek, M. R.; Singh, P. K. Bacterial biofilms: an emerging link to disease pathogenesis. Annu. Rev. Microbiol. 2003, 57, 677-701.

(21) Costerton, J. W. Cystic fibrosis pathogenesis and the role of biofilms in persistent infection. Trends Microbiol. 2001, 9, 50-52.

(22) Costerton, J. W.; Stewart, P. S.; Greenberg, E. P. Bacterial biofilms: a common cause of persistent infections. Science 1999, 284, 131813122.

(23) Ratliff, M.; Zhu, W.; Deshmukh, R.; Wilks, A.; Stojiljkovic, I. Homologues of neisserial heme oxygenase in Gram-negative bacteria: degradation of heme by the product of the pigA gene of Pseudomonas aeruginosa. J. Bacteriol. 2001, 183, 6394-6403.

(24) Friedman, J.; Lad, L.; Deshmukh, R.; Li, H.; Wilks, A.; Poulos, T. L. Crystal structures of the NO- and CO-bound heme oxygenase from Neisseriae meningitidis. Implications for $\mathrm{O}_{2}$ activation. J. Biol. Chem. 2003, 278, 34654-34659.

(25) Friedman, J.; Lad, L.; Li, H.; Wilks, A.; Poulos, T. L. Structural basis for novel delta-regioselective heme oxygenation in the opportunistic pathogen Pseudomonas aeruginosa. Biochemistry 2004, 43, 5239-5245.

(26) Schuller, D. J.; Wilks, A.; Ortiz de Montellano, P. R.; Poulos, T. L. Crystal structure of human heme oxygenase-1. Nat. Struct. Biol. 1999 6, 860-867.

(27) Schuller, D. J.; Zhu, W.; Stojiljkovic, I.; Wilks, A.; Poulos, T. L. Crystal structure of heme oxygenase from the Gram-negative pathogen Neisseria meningitidis and a comparison with mammalian heme oxygenase-1. Biochemistry 2001, 40, 11552-11558.

(28) Braun, V.; Braun, M. Active transport of iron and siderophore antibiotics. Curr. Opin. Microbiol. 2002, 5, 194-201.

(29) Gohlke, H.; Klebe, G. Statistical potentials and scoring functions applied to protein-ligand binding. Curr. Opin. Struct. Biol. 2001, $11,231-235$

(30) Leach, A. R.; Shoichet, B. K.; Peishoff, C. E. Prediction of proteinligand interactions. Docking and scoring: successes and gaps. J. Med. Chem. 2006, 49, 5851-5855.

(31) Chen, I.-J.; Neamati, N.; MacKerell, A. D., Jr. Structure-based inhibitor design targeting HIV-1 integrase. Curr. Drug Targets: Infect. Disord. 2002, 2, 217-234.

(32) Markowitz, J.; Chen, I.; Gitti, R.; Baldisseri, D. M.; Pan, Y.; Udan, R.; Carrier, F.; MacKerell, A. D., Jr.; Weber, D. J. Identification and characterization of small molecule inhibitors of the calciumdependent S100B-p53 tumor suppressor interaction. J. Med. Chem. 2004, 47, 5085-5093.
(33) Hancock, C. N.; Macias, A. T.; Lee, E. K.; Yu, S. Y.; MacKerell, A. D., Jr.; Shapiro, P. Identification of novel extracellular signalregulated kinase (ERK) docking domain inhibitors. J. Med. Chem. 2005, 48, 4586-4595.

(34) Pan, Y.; Huang, N.; Cho, S.; MacKerell, A. D., Jr. Consideration of molecular weight during compound selection in virtual target-based database screening. J. Chem. Inf. Comput. Sci. 2003, 43, 267-272.

(35) Teague, S. J.; Davis, A. M.; Leeson, P. D.; Oprea, T. The design of leadlike combinatorial libraries. Angew. Chem., Int. Ed. 1999, 38, 3743-3748.

(36) Opera, T. I. Property distribution of drug-related chemical databases. J. Comput.-Aided Mol. Des. 2000, 14, 251-264.

(37) Oprea, T. I.; Davis, A. M.; Teague, S. J.; Leeson, P. D. Is there a difference between leads and drugs? A historical perspective. J. Chem. Inf. Comput. Sci. 2001, 41, 1308-1315.

(38) Huang, N.; Nagarsekar, A.; Xia, G.; Hayashi, J.; MacKerell, A. D., Jr. Identification of inhibitors targeting the $\mathrm{pY}+3$ binding site of the tyrosine kinase p531ck SH2 domain. J. Med. Chem. 2004, 47, 35023511 .

(39) Chen, F.; Hancock, C. N.; Macias, A. T.; Joh, J.; Still, K.; Zhong, S.; MacKerell, A. D., Jr.; Shapiro, P. Characterization of ATPindependent ERK inhibitors identified through in silico analysis of the active ERK2 structure. Bioorg. Med. Chem. Lett. 2006, 16, 62816287.

(40) Drummond, G. S.; Kappas, A. Prevention of neonatal hyperbilirubinemia by tin protoporphyrin IX, a potent competitive inhibitor of heme oxidation. Proc. Natl. Acad. Sci. U.S.A. 1981, 78, 6466-6470.

(41) Vreman, H. J.; Cipkala, D. A.; Stevenson, D. K. Characterization of porphyrin heme oxygenase inhibitors. Can. J. Physiol. Pharmacol. 1996, 74, 278-285.

(42) Vreman, H. J.; Ekstrand, B. C.; Stevenson, D. K. Selection of metalloporphyrin heme oxygenase inhibitors based on potency and photoreactivity. Pediatr. Res. 1993, 33, 195-200.

(43) Vreman, H. J.; Rodgers, P. A.; Stevenson, D. K. Zinc protoporphyrin administration for suppression of increased bilirubin production by iatrogenic hemolysis in rhesus neonates. J. Pediatr. 1990, 117, 292297.

(44) Trakshel, G. M.; Sluss, P. M.; Maines, M. D. Comparative effects of tin- and zinc-protoporphyrin on steroidogenesis: tin-protoporphyrin is a potent inhibitor of cytochrome P-450-dependent activities in the rat adrenals. Pediatr. Res. 1992, 31, 196-201.

(45) Luo, D.; Vincent, S. R. Metalloporphyrins inhibit nitric oxidedependent cGMP formation in vivo. Eur. J. Pharmacol. 1994, 267, 263-267.

(46) Glaum, S. R.; Miller, R. J. Zinc protoporphyrin-IX blocks the effects of metabotropic glutamate receptor activation in the rat nucleus tractus solitarii. Mol. Pharmacol. 1993, 43, 965-969.

(47) Vlahakis, J. Z.; Kinobe, R. T.; Bowers, R. J.; Brien, J. F.; Nakatsu, K.; Szarek, W. A. Imidazole-dioxolane compounds as isozymeselective heme oxygenase inhibitors. J. Med. Chem. 2006, 49, 44374441.

(48) Walker, K. A.; Kertesz, D. J.; Rotstein, D. M.; Swinney, D. C.; Berry, P. W.; So, O. Y.; Webb, A. S.; Watson, D. M.; Mak, A. Y.; Burton, P. M.; et al. Selective inhibition of mammalian lanosterol 14 alphademethylase: a possible strategy for cholesterol lowering. J. Med. Chem. 1993, 36, 2235-2237.

(49) Chu, G. C.; Katakura, K.; Zhang, X.; Yoshida, T.; Ikeda-Saito, M. Heme degradation as catalyzed by a recombinant bacterial heme oxygenase (Hmu O) from Corynebacterium diphtheriae. J. Biol. Chem. 1999, 274, 21319-21325.

(50) Wilks, A.; Torpey, J.; Ortiz de Montellano, P. R. Heme oxygenase (HO-1). Evidence for electrophilic oxygen addition to the porphyrin ring in the formation of alpha-meso-hydroxyheme. J. Biol. Chem 1994, 269, 29553-29556.

(51) Zhu, W.; Wilks, A.; Stojiljkovic, I. Degradation of heme in Gramnegative bacteria: the product of the hemO gene of Neisseriae is a heme oxygenase. J. Bacteriol. 2000, 182, 6783-6790.

(52) Lansky, I. B.; Lukat-Rodgers, G. S.; Block, D.; Rodgers, K. R.; Ratliff, M.; Wilks, A. The cytoplasmic heme-binding protein (PhuS) from the heme uptake system of Pseudomonas aeruginosa is an intracellular heme-trafficking protein to the $\delta$-regioselective heme oxygenase. J. Biol. Chem. 2006, 281, 13652-13662.

(53) Bhakta, M. N.; Wilks, A. The mechanism of heme transfer from the cytoplasmic heme binding protein PhuS to the delta-regioselective heme oxygenase of Pseudomonas aeruginosa. Biochemistry 2006, 45, 11642-11649.

(54) Skaar, E. P.; Humayun, M.; Bae, T.; DeBord, K. L.; Schneewind, O. Iron-source preference of Staphylococcus aureus infections. Science 2004, 305, 1626-1628.

(55) Cope, L. D.; Yogev, R.; Muller-Eberhard, U.; Hansen, E. J. A gene cluster involved in the utilization of both free heme and heme: hemopexin by Haemophilus influenzae type b. J. Bacteriol. 1995 , 177, 2644-2653. 
(56) Olczak, T.; Simpson, W.; Liu, X.; Genco, C. A. Iron and heme utilization in Porphyromonas gingivalis. FEMS Microbiol. Rev. 2005, 29, 119-144

(57) Heijerman, H. Infection and inflammation in cystic fibrosis: a short review. J. Cystic Fibrosis 2005, 4 (Suppl. 2), 3-5.

(58) Ran, H.; Hassett, D. J.; Lau, G. W. Human targets of Pseudomonas aeruginosa pyocyanin. Proc. Natl. Acad. Sci. U.S.A. 2003, 100, 14315-14320

(59) Zhou, H.; Lu, F.; Latham, C.; Zander, D. S.; Visner, G. A. Heme oxygenase-1 expression in human lungs with cystic fibrosis and cytoprotective effects against Pseudomonas aeruginosa in vitro. Am. J. Respir. Crit. Care Med. 2004, 170, 633-640.

(60) Sirois, S.; Hatzakis, G.; Wei, D.; Du, Q.; Chou, K. C. Assessment of chemical libraries for their druggability. Comput. Chem. Biol. 2005, 29, 55-67.

(61) Li, J.; Zhu, T.; Cramer, C. J.; Truhlar, D. G. A new class IV charge model for extracting accurate partial charges from wave functions. J. Phys. Chem. A 1998, 102, 1820-1831.

(62) Markowitz, J.; MacKerell, A. D., Jr.; Carrier, F.; Charpentier, T. H.; Weber, D. J. Design of inhibitors of S100B. Curr. Top. Med. Chem. 2005, 5, 1093-1108.

(63) Brooks, B. R.; Bruccoleri, R. E.; Olafson, B. D.; States, D. J.; Swaminathan, S.; Karplus, M. CHARMM: a program for macromolecular energy, minimization, and dynamics calculations. $J$. Comput. Chem. 1983, 4, 187-217.

(64) MacKerell, A. D., Jr.; Brooks, B.; Brooks, C. L., III; Nilsson, L.; Roux, B.; Won, Y.; Karplus, M. CHARMM: The Energy Function and Its Paramerization with an Overview of the Program. In Encyclopedia of Computational Chemistry; Schleyer, P. v. R., Allinger, N. L., Clark, T., Gasteiger, J., Kollman, P. A., Schaefer, H. F., III, Schreiner, P. R., Eds.; John Wiley \& Sons: Chichester, U.K., 1998; Vol. 1, pp 271-277.

(65) MacKerell, A. D., Jr.; Bashford, D.; Bellott, M.; Dunbrack, R. L., Jr.; Evanseck, J.; Field, M. J.; Fischer, S.; Gao, J.; Guo, H.; Ha, S.; Joseph, D.; Kuchnir, L.; Kuczera, K.; Lau, F. T. K.; Mattos, C.; Michnick, S.; Ngo, T.; Nguyen, D. T.; Prodhom, B.; Reiher, I., W. E.; Roux, B.; Schlenkrich, M.; Smith, J.; Stote, R.; Straub, J.; Watanabe, M.; Wiorkiewicz-Kuczera, J.; Yin, D.; Karplus, M. Allatom empirical potential for molecular modeling and dynamics studies of proteins. J. Phys. Chem. B 1998, 102, 3586-3616.

(66) MacKerell, A. D., Jr.; Feig, M.; Brooks, C. L., III. Accurate treatment of protein backbone conformational energetics in empirical force fields. J. Am. Chem. Soc. 2004, 126, 698-699.

(67) MacKerell, A. D., Jr.; Feig, M.; Brooks, C. L., III. Extending the treatment of backbone energetics in protein force fields: limitations of gas-phase quantum mechanics in reproducing protein conformational distributions in molecular dynamics simulations. J. Comput. Chem. 2004, 25, 1400-1415.

(68) Jorgensen, W. L.; Chandrasekhar, J.; Madura, J. D.; Impey, R. W.; Klein, M. L. Comparison of simple potential functions for simulating liquid water. J. Chem. Phys. 1983, 79, 926-935.

(69) Field, M. J.; Karplus, M. CRYSTAL Module of CHARMM, 22; Harvard University: Cambridge, MA, 1992.

(70) Darden, T. A.; York, D.; Pedersen, L. G. Particle mesh Ewald: an $\mathrm{N} \log (\mathrm{N})$ method for Ewald sums in large systems. J. Chem. Phys. 1993, 98, 10089-10092.
(71) Steinbach, P. J.; Brooks, B. R. New spherical-cutoff methods of longrange forces in macromolecular simulations. J. Comput. Chem. 1994, $15,667-683$.

(72) Ryckaert, J.-P.; Ciccotti, G.; Berendsen, H. J. C. Numerical integration of the Cartesian equations of motion of a system with constraints: molecular dynamics of $n$-alkanes. J. Comput. Phys. 1977, 23, 327341.

(73) Feller, S. E.; Zhang, Y.; Pastor, R. W.; Brooks, R. W. Constant pressure molecular dynamics simulation: the Langevin piston method. J. Chem. Phys. 1995, 103, 4613-4621.

(74) Berman, H. M.; Westbrook, J.; Feng, Z.; Gilliland, G.; Bhat, T. N.; Weissig, H.; Shindyalov, I. N.; Bourne, P. E. The Protein Data Bank. Nucleic Acids Res. 2000, 28, 235-242.

(75) Nosé, S. A unified formulation of the constant temperature molecular dynamics method. J. Chem. Phys. 1984, 81, 511-519.

(76) Meng, E. C.; Shoichet, B. K.; Kuntz, I. D. Automated docking with grid-based energy evaluation. J. Comput. Chem. 1992, 13, 505-524.

(77) Leach, A. R.; Kuntz, I. D. Conformational analysis of flexible ligands in macromolecular receptor sites. J. Comput. Chem. 1992, 13, 730748.

(78) Connolly, M. L. Solvent-accessible surfaces of proteins and nucleic acids. Science 1983, 221, 709-713.

(79) Ferrin, T. E.; Huang, C. C.; Jarvis, L. E.; Langridge, R. The MIDAS display system. J. Mol. Graphics 1988, 6, 13-27.

(80) Goodford, P. J. A computational procedure for determining energetically favorable binding sites on biologically important macromolecules. J. Med. Chem. 1984, 28, 849-857.

(81) Ewing, T. J. A.; Kuntz, I. D. Critical evaluation of search algorithms used in automated molecular docking. J. Comput. Chem. 1997, 18, 1175-1189.

(82) Godden, J. W.; Stahura, F. L.; Bajorath, J. Variability of molecular descriptors in compound databases revealed by Shannon entropy calculations. J. Chem. Inf. Comput. Sci. 2000, 40, 796-800.

(83) Lipinski, C. A. Drug-like properties and the causes of poor solubility and poor permeability. J. Pharmacol. Toxicol. Methods 2000, 44 , 235-249.

(84) Demange, P.; Bateman, A.; Mertz, C.; Dell, A.; Piemont, Y.; Abdallah, M. A. Bacterial siderophores: structures of pyoverdins Pt, siderophores of Pseudomonas tolaasii NCPPB 2192, and pyoverdins Pf, siderophores of Pseudomonas fluorescens CCM 2798. Identification of an unusual natural amino acid. Biochemistry 1990, 29, 11041-11051.

(85) Sakamoto, H.; Omata, Y.; Adachi, Y.; Palmer, G.; Noguchi, M. Separation and identification of the regioisomers of verdoheme by reversed-phase ion-pair high-performance liquid chromatography, and characterization of their complexes with heme oxygenase. J. Inorg. Biochem. 2000, 82, 113-121.

(86) Bradford, M. M. A rapid and sensitive method for the quantitation of microgram quantities of protein utilizing the principle of proteindye binding. Anal. Biochem. 1976, 72, 248-254.

(87) Sambrook, J.; Fritsch, E. F.; Maniatis, T. Molecular Cloning: A Laboratory Manual; Cold Spring Harbor Laboratory: Cold Spring Harbor, NY, 1989.

JM0700969 